\title{
Mudança Conceitual em Óptica Geométrica Facilitada Pelo Uso de TDIC
}

\author{
João B. da Silva ${ }^{1}$, Gilvandenys L. Sales ${ }^{1}$, Eliana A. M. Leite ${ }^{1}$, Luiza S. Pontello ${ }^{1}$ \\ ${ }^{1}$ Instituto Federal do Ceará (IFCE) \\ Av 13 de Maio, 2081 - 60.040-215 - Fortaleza - CE - Brasil \\ joaobathista82@hotmail.com, \{denyssales, elimoreiraead\}@gmail.com, \\ lpontello@yahoo.com.br
}

\begin{abstract}
The aim of this paper is to propose a conceptual model of change that can facilitate the teaching and learning process through a collaborative learning model supported by computer based on a model of constructivist education and the 5 C's methodology (SALES, 2005). Digital Technologies, particularly the Learning Object (OA), are used as an educational tool to assist students in building new representations that can change their preconceptions when they face conflicting situations in which feels the need to build new representations. The results showed that the methodology and teaching resources in Geometrical Optics classes facilitated the process of conceptual change.
\end{abstract}

Resumo. O objetivo do artigo é propor um modelo de mudança conceitual que possa facilitar o processo de ensino e aprendizagem por meio de um modelo de aprendizagem colaborativa apoiada por computador baseada em um modelo de educação construtivista e na metodologia dos 5 C's (SALES, 2005). Tecnologias Digitais, em particular os OA, são usados como ferramenta pedagógica para auxiliar os alunos na construção de novas representações que podem mudar suas concepções prévias frente a situações conflitivas onde há a necessidade de se construir novas representações. Os resultados apontam que a metodologia e os recursos pedagógicos nas aulas de Óptica Geométrica facilitaram o processo de mudança conceitual.

\section{Introdução}

A difusão da tecnologia digital nas últimas décadas do século XX proporcionou uma mudança radical na educação. Alunos contemporâneos do ensino médio representam a geração que cresceu cercado pelas novas tecnologias. Eles passam a maior parte do tempo usando computadores, vídeo games, câmeras de vídeo, telefones celulares e todas as outras ferramentas da era digital.

Esse quadro é representativo do avanço da das Tecnologias Digitais de Informação e Comunicação (TDIC) tanto no que concerne às descobertas nessa área como no que diz respeito à propagação de seu uso. Como consequência desse cenário, surge a necessidade de que os espaços de aprendizagem, sejam na escola ou fora dela, apropriem-se de seus recursos, tais como os objetos de aprendizagem (OA) e os ambientes virtuais. 
Com vistas a contribuir com essa demanda, o objetivo desse trabalho é propor um modelo de mudança conceitual como estratégia facilitadora dos processos de ensino e de aprendizagem. Esse modelo consiste em confrontar os conceitos já adquiridos pelo educando com os conceitos científicos e formais, por meio de conflitos empíricos, levando-o a uma reconstrução desses conceitos iniciais.

Essa estratégia é baseada nos princípios construtivistas de educação, buscando auxiliar os alunos na (re)construção de representações que podem mudar suas concepções prévias quando no enfrentamento de situações conflitivas. Será utilizado, para isso, o Procedimento Cognitivo Metodológico de Apreensão (PCMA), com base na proposta de Pozo (1998) e sugerida por Sales (2005).

Com o intuito de desenvolver as discussões teóricas necessárias para a aplicação da metodologia citada, na seção 2 explicita-se as etapas da metodologia PCMA, na seção 3, relata-se a metodologia e os passos da pesquisa, na seção 4 elabora-se a análise de dados e, por fim, tece-se as considerações finais.

\section{PCMA: Modelo de Mudança Conceitual Proposto}

O modelo de mudança conceitual proposto pelo Procedimento Cognitivo Metodológico de Apreensão (PCMA), ou modelo dos 5C's, inicialmente proposto para Física Quântica (SALES, 2005), ora adaptado neste trabalho para Óptica, deverá ser norteada pelas seguintes fases (Figura 1):

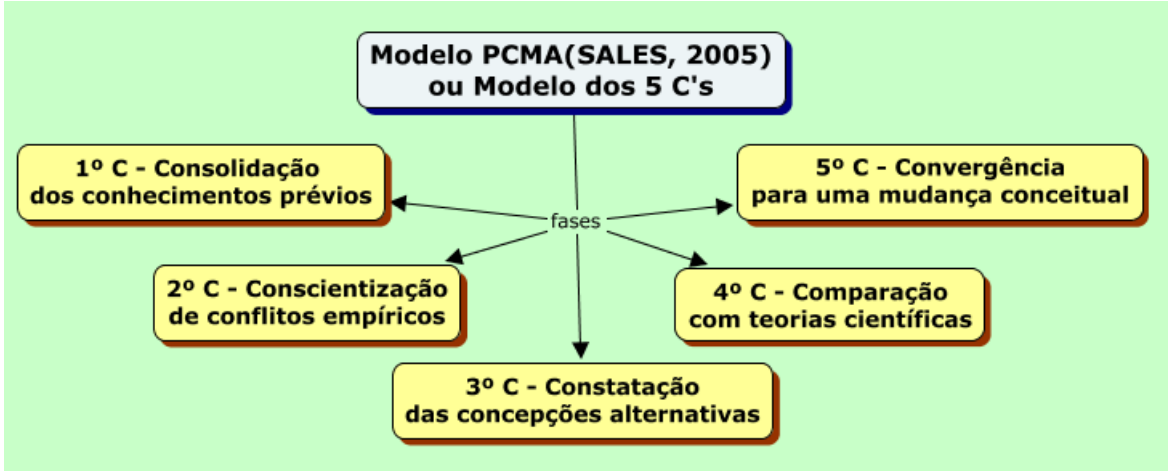

Figura 1 - Modelo de mudança conceitual PCMA

Fonte: próprio autor

\subsection{Consolidação dos Conhecimentos Prévios}

Certificação de que o aluno já domina e sabe as teorias e conceitos ligados ao conteúdo a ser ensinado; A vida cotidiana do aluno é a parte mais importante para incorporar novos conhecimentos na estrutura cognitiva do indivíduo, é deste cotidiano que o aluno adquire seus conhecimentos prévios que são levados para dentro da sala de aula no momento do aprendizado.

Segundo Moreira (2012) a organização do conhecimento prévio em um dado corpo de conhecimentos, em certo momento, é o que mais influencia a aquisição significativa de novos conhecimentos nessa área, em um processo interativo no qual o novo ganha significados, se integra e se diferencia em relação ao já existente que, por sua vez, adquire novos significados, fica mais estável, mais diferenciado, mais rico e mais capaz de ancorar novos conhecimentos.

A aprendizagem é muito mais significativa à medida que o novo conteúdo é incorporado às estruturas de conhecimento de um aluno e adquire significado para ele a 
partir da relação com seu conhecimento prévio. Sendo assim, é graças aos conhecimentos prévios do aluno que este pode fazer uma leitura inicial do novo conteúdo, atribuindo-lhe um primeiro nível de significado para então iniciar seu processo de aprendizagem.

Tudo aquilo que o indivíduo aprende deveria se integrar naquilo que o sujeito já conhece e isso deveria ser aplicado nas várias áreas do ensino. Além disso, é importante que a estrutura cognitiva particular do aprendiz contenha ideias ancoradas relevantes, com as quais se possam relacionar (AUSUBEL, 1983).

\subsection{Conscientização de Conflitos Empíricos}

Para que haja uma conscientização de conflitos empíricos é necessário modificar seus esquemas, para modificar seus esquemas o aluno precisa perceber a situação conflitiva entre os conceitos antigos e os novos conceitos; sendo assim, a partir desse momento o aluno precisa perceber a situação conflitiva entre os conceitos prévios vivenciados no seu cotidiano e os conceitos de natureza científica proposto pela óptica geométrica.

De acordo com a teoria piagetiana, para que ocorra o processo de aprendizagem, o aluno terá que transpor seus conflitos cognitivos, preenchendo as lacunas apresentadas devido a falta de conhecimento sobre o conteúdo.

O aluno quando entra em contato com o novo objeto do conhecimento pode ficar em conflito com esse objeto, no sentido de "desequilibrado". É no momento de desequilíbrio do sujeito que o conflito é estabelecido, ou seja, quando um esquema já pronto nas estruturas cognitivas do indivíduo passa a não contemplar mais as situações nas quais ele está inserido. Nesse instante, é necessário que ele desenvolva e transforme seus esquemas mentais para que então possa resolver a nova situação e o equilíbrio se reestabeleça.

A destreza dos alunos em resolver esses conflitos na vida escolar depende em parte de mudar os seus esquemas. Em essência, os esquemas são usados como um molde para as experiências de vida de um indivíduo e para a maneira como ele processa a informação.

As situações conflitivas são estratégias que podem ser usadas com o propósito de produzir no aprendiz uma insatisfação com suas concepções prévias. Elas resultam da incapacidade do sujeito de resolver problemas produzidos em sua interação com o meio.

O ensino baseado no conflito cognitivo como elemento da mudança conceitual é a característica de uma posição construtivista da aprendizagem, no qual a meta da educação científica é mudar as concepções prévias e substituí-las pelo conhecimento científico.

\subsection{Constatação das Concepções Alternativas}

Auxiliado pelo professor faz-se uma reestruturação teórica na busca de teorias alternativas para melhor justificar o fenômeno em estudo; após criar uma situação de conflito na mente do aluno é necessário que o professor constate as suas concepções alternativas (conhecimentos prévios), auxilie-os a fazer uma reestruturação teórica e os conduzam na busca de teorias alternativas para melhor justificar o fenômeno físico estudado em sala de aula. 
Para auxiliar seus alunos, os professores devem ser, antes de tudo, mediadores e agentes de motivação daquilo que se quer ensinar. Para ensinar algo a um aluno, este deve ter qualquer motivo para aprender (SALES, 2005).

A interação professor com o aluno em sala de aula é um ponto importante que fomenta a construção do conhecimento. Professores devem deixar de ser meros transmissores de informações e passarem a ser mais um motivador, um orientador de todos os processos relativos à construção do conhecimento, estando cientes de que o conhecimento se desenvolve determinado pelas ações mútuas entre os professores e os alunos.

Ao chegar à sala de aula o aluno já traz na sua mente conceitos pré estabelecidos, para Ausubel, essas concepções muitas das vezes são equivocadas ou distanciadas do conhecimento científico aceito, além disso, podem tornar-se ainda mais consistentes se o processo de ensino não for eficiente (AUSUBEL et al., 1980), por isso o professor precisa ter a sensibilidade para enxergar a necessidade dos alunos e assim auxiliá-los no processo de ensino.

$\mathrm{Na}$ maioria dos casos essas concepções alternativas têm várias origens ligadas diretamente à influência das experiências cotidianas, a influência da linguagem oral e escrita, e a influência dos meios de comunicação com rádio, TV, cinema, livros etc.

Para que a aprendizagem seja facilitada o professor deve começar com uma visão geral, em nível de abstração mais alto, do conteúdo a ser estudado, procurando fazer a "ponte" entre aquilo que o aluno já sabe e o que ele precisa saber para aprender significativamente conteúdo de aula (MOREIRA, 2012).

Conforme Pozo (1998), tanto os adultos como os adolescentes sustentam concepções errôneas sobre muitos fenômenos científicos, sejam físico-naturais, sociais ou históricos. Sendo assim, em muitos casos, tais sujeitos têm sido submetidos a uma prolongada instrução científica que, no entanto, não modifica suas concepções espontâneas (ALEGRO, 2008).

\subsection{Comparação com as Teorias Científicas}

Formulam-se e apresentam-se as novas teorias advindas da Óptica Geométrica, após o professor auxiliar seus alunos para que eles façam uma reestruturação teórica e busquem teorias alternativas para melhor justificar o fenômeno físico estudado em sala de aula. Os alunos devem formular e apresentar as novas teorias advindas com a óptica geométrica.

Quando é dado para a turma problemas para serem resolvidos que exigem um conhecimento científico, eles tentam resolver com base em seus esquemas o que levam os alunos a manifestarem suas concepções prévias. É bem evidente que as respostas dos alunos estão baseadas no conhecimento prévio que estes possuem e esse conhecimento é fortemente influenciado pelo ambiente social em que vivem.

O processo de integração de novos conteúdos, ou seja, de novos conceitos à estrutura cognitiva do aluno ao ser comparado com os conhecimentos prévios constituem uma condição própria e necessária do processo de construção de conceitos científicos. 


\subsection{Convergência para Mudança Conceitual}

Auxiliado pelo uso do recurso pedagógico o aluno modifica então suas concepções prévias. De acordo com Pozo (1998): "Ensinar ciências não consiste em proporcionar conceitos aos alunos, mas em mudar os que eles já possuem".

Os alunos costumam trazer para a sala de aula concepções, ideias e intuições que foram construídos no decorrer de suas experiências no convívio em seu grupo sociocultural, ou seja, no seu cotidiano. Essas concepções espontâneas dos alunos são muito persistentes e resistem às mudanças conceituais, principalmente se os conceitos científicos conflitam com elas. Somente através de estratégias didáticas bem concebidas poderão se transformar em conceitos cientificamente correto (SALES, 2005).

Dessa forma, destaca-se que, de acordo com a teoria piagetiana, o conceito de mudança conceitual esta relacionada à ideia de "adaptação intelectual", ou seja, é um estabelecimento de equilíbrio progressivo entre um mecanismo assimilador e uma acomodação complementar.

De acordo com Posner et al. (1982) a mudança conceitual se propõe inicialmente a explicar ou descrever as dimensões substantivas do processo pelo qual os conceitos centrais e organizadores das pessoas mudam de um conjunto de conceitos a outro conjunto, incompatível com o anterior.

\section{A abordagem Pedagógica -Curricular}

A amostra desse estudo foi constituída por 24 alunos do $4^{\circ}$ período do curso integrado de química do Instituto Federal de Educação, Ciência e Tecnologia do Ceará (IFCE). O conteúdo vivenciado foi Óptica Geométrica.

As atividades realizadas foram: construção de páginas hipertextuais, oficina de espelhos planos, desafios, quizzes (questionário online), e simulações virtuais.

\subsection{Construção de páginas hipertextuais}

Dentre as principais características do hipertexto, pode-se citar o fato dele ser intertextual, dinâmico, multilinear e interativo. Os sites, que fazem parte do nosso cotidiano e nos conectam ao mundo, são bons exemplos práticos de uma estrutura hipertextual.

Para detectar os conhecimentos prévios trazidos pelos alunos para dentro da sala de aula, foi proposto que os alunos construíssem uma página hipertextual cujo título foi: Por que o ano 2015 é considerado o Ano Internacional da LUZ?

A turma foi dividida em times, cada time com quatro participantes. $\mathrm{O}$ objetivo de dividir a Tuma em times foi incentivar a interação entre os colegas, onde o aluno que sabe mais possa colaborar com o que sabe menos alimentando assim o espírito colaborativo.

Para construção do hipertexto foi proposto que cada time deveria fazer pelo menos duas edições. $\mathrm{O}$ hipertexto foi feito pelos alunos em meio eletrônico no endereço (http://www.helpclassonline.com.br/moodle) e proporcionou o acesso à outras páginas web, imagens, vídeos, músicas, sites diversos por meio de hiperlinks.

A apresentação do hipertexto em sala possibilitou de forma significativa detectar as ideias prévias dos alunos sobre alguns fenômenos a serem estudados no decorrer do semestre. 


\subsection{Oficina de espelhos planos}

No segundo momento, após detectar alguns dos conhecimentos prévios trazidos pelos alunos, foi realizada uma oficina de espelhos planos (EP), para dar suporte à atividade foi usado um roteiro de trabalho auxiliado com um mapa conceitual sobre óptica geométrica. Na oficina foram usados aparatos experimentais de baixo custo cujo objetivo foi que os alunos manipulassem os objetos despertando assim a curiosidade.

O propósito da oficina foi colocar o aluno em situação de conflito entre os conceitos prévios vivenciados no seu cotidiano e os conceitos de natureza científica proposto pela óptica geométrica. Ou seja, para o aluno compreender os novos experimentos durante a oficina foi necessário modificar seus esquemas para absorver os novos conceitos científicos da óptica geométrica.

Auxiliados pelo professor com o uso dos espelhos planos os alunos observaram as características das imagens formadas pelos mesmos.

A oficina deu uma vertente lúdica para introduzir o conteúdo que seria mais para despertar a curiosidade do aluno, trabalhando assim seus conceitos prévios e servindo de ponte para uma linguagem científica.

\subsection{Aprendizagem Baseada em Problemas e Desafios}

Para se consolidar os conhecimentos foram propostos também desafios para a turma. Esses desafios foram constituídos de problemas propostos.

A turma foi gamificada, ou seja, houve a utilização de elementos do design de games em contextos que não são de games. Esses elementos foram interação, colaboração, motivação, fases, feedback, prêmios etc.

Os desafios foram questões propostas para que os alunos tentassem responder em times, cada time com quatro participantes. O time pontuava quando respondia a questão correta. Porém, quando não acertava a questão, a mesma questão era passada para os demais times, e o time que respondesse pontuava. É importante destacar que se nenhum time conseguisse responder a questão, o professor iria explicar.

Ao serem desafiados os alunos se sentiram motivados, estimulados a aprender, além do mais, houve um aumento significativo do interesse pelas aulas e pela realização das tarefas.

\subsection{Simulações experimentais com Software Educacional}

Na sala de aula surgem os objetos de aprendizagem (OA) como uma alternativa, não de substituir o laboratório real pelo virtual, mas de incrementar mais um recurso pedagógico a ser utilizado pela escola.

Adota-se o conceito de objeto de aprendizagem utilizado por Sales (2012) "OA é uma espécie de "partícula" ou "Tijolo Didático" reutilizável de conteúdo educacional digital que pode compor uma unidade de aprendizagem."

Foi usado um objeto de aprendizagem virtual para simular o comportamento de uma lente convergente. Esse software educacional esta hospedado na plataforma $\mathrm{PhET}$ e está disponível no endereço (http:// phet.colorado.edu).

Os objetivos desse software são explicar como uma imagem é formada por uma lente (Figura 2). 
CBIE-LACLO 2015

Anais do XXI Workshop de Informática na Escola (WIE 2015)

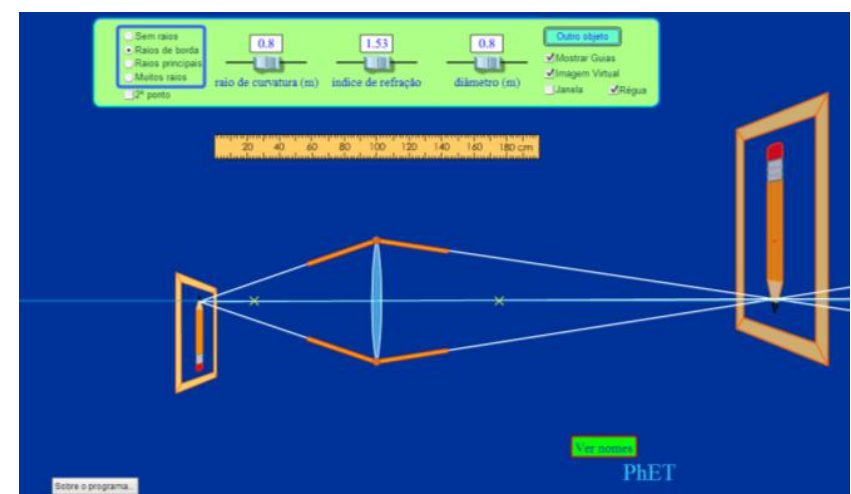

Figura 2 - Objeto de Aprendizagem sobre lentes

Fonte: http://phet.colorado.edu/sims/geometric-optics/geometric-optics pt.html

Durante a simulação percebeu-se que os alunos ao utilizarem o OA puderam interferir no sistema de acordo as teorias ou modelos que descrevem o seu funcionamento real. Ao tentar resolver o problema com base em seus esquemas, o aluno é levado a manifestar suas concepções prévias sendo necessário fazer uma reestruturação teórica para melhor justificar o fenômeno e conceber novas teorias da óptica geométrica.

\subsection{Quizzes - questionários online}

Foi elaborado e aplicado um Quiz (Questionário Eletrônico online) ao final de cada tópico de óptica. A sala de aula virtual usada foi o Moodle.

Os objetivos dos quizzes durante as aulas foram avaliar, estimular e facilitar o aprendizado dos alunos, tornando o ensino mais dinâmico e aumentando o interesse pela disciplina.

As perguntas foram cuidadosamente arranjadas tornando a atividade lúdica, procurando melhorar dessa forma, o processo de ensino e de aprendizagem. Além disso, o Quiz facilitou correções e possibilitou um feedback, o que melhorou a interação professor/aluno e isso é muito importante no processo de aprendizagem.

\section{Análise dos Dados}

A primeira parte da pesquisa consistiu em observação da turma bem como seu acompanhamento durante o todo o semestre. Durante a segunda parte do trabalho foi elaborado e aplicado um questionário nos alunos no final do semestre.

O questionário foi elaborado e composto por quarenta perguntas que foram divididas em sete partes: 1 - dados de satisfação com a disciplina de Física; 2 satisfação com a metodologia utilizada pelo professor; 3 - opinião sobre uso de oficinas durante as aulas; 4 - interação com os alunos da turma; 5 - método de avaliação e o uso de Quiz; 6 - os desafios propostos; 7 - a importância da disciplina no seu cotidiano. Cada pergunta proposta foi avaliadas por uma escala Likert de cinco pontos: concordo totalmente $(\mathrm{CT})$, concordo parcialmente $(\mathrm{CP})$, indiferente (I), discordo parcialmente (DP) e discordo totalmente (DT).

Em resposta à questão "se os alunos se sentem estimulados a aprender mais quando são propostos desafios durante as atividades" (Gráfico 1), de acordo com as respostas pode-se verificar que a maioria dos alunos se sente estimulado a aprender quando são desafiados, já que $57 \%$ da turma respondeu concordo totalmente, $29 \%$ concordo parcialmente, $7 \%$ foi indiferente e $7 \%$ discorda parcialmente. 
CBIE-LACLO 2015

Anais do XXI Workshop de Informática na Escola (WIE 2015)

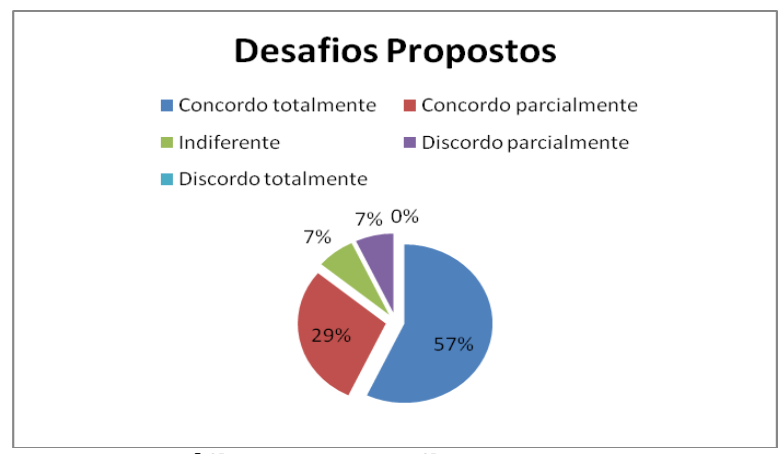

Gráfico 1 - Desafio Propostos

Com o propósito de analisar a avaliação dos alunos sobre a construção das página hipertextuais sobre o ano internacional da luz no processo de mudança conceitual e o uso de TDIC verificou-se que antes das aulas, a maioria dos alunos ainda não haviam construído uma página hipertextual, já que apenas $14 \%$ da turma respondeu concordo totalmente, $7 \%$ concordo parcialmente, $7 \%$ foi indiferente, $7 \%$ discorda parcialmente e $65 \%$ discorda totalmente (Gráfico 2).

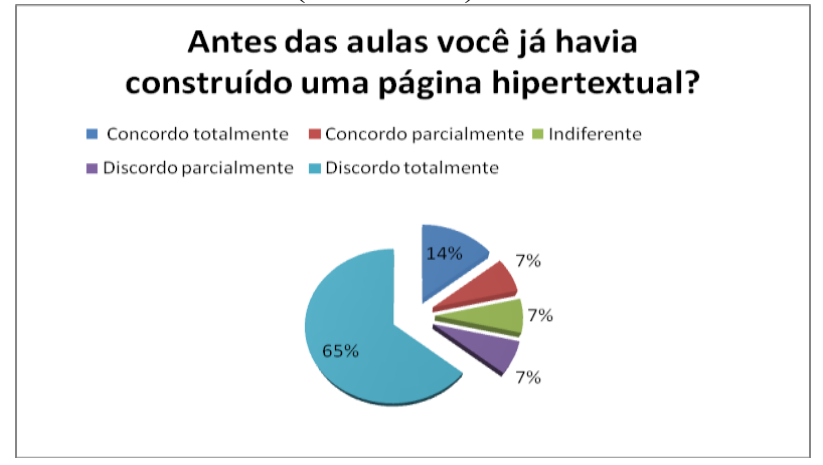

Gráfico 2 - Construção de páginas hipertextuais

Vale destacar que o mais importante nesse processo de construção de hipertextos foi deixar o aluno à vontade para expressar seus conhecimentos prévios. Os resultados mostraram que a maioria deles gostou da atividade, bem como revelou ampla participação, o que é essencial para da início ao processo de mudança de conceitos.

Com relação à avaliação das oficinas de espelhos planos contatou-se que a oficina estimula a aprendizagem: $64 \%$ da turma respondeu concordo totalmente, $29 \%$ concordo parcialmente, $7 \%$ foi indiferente, $0 \%$ discorda parcialmente e $0 \%$ discorda totalmente (Gráfico 3).

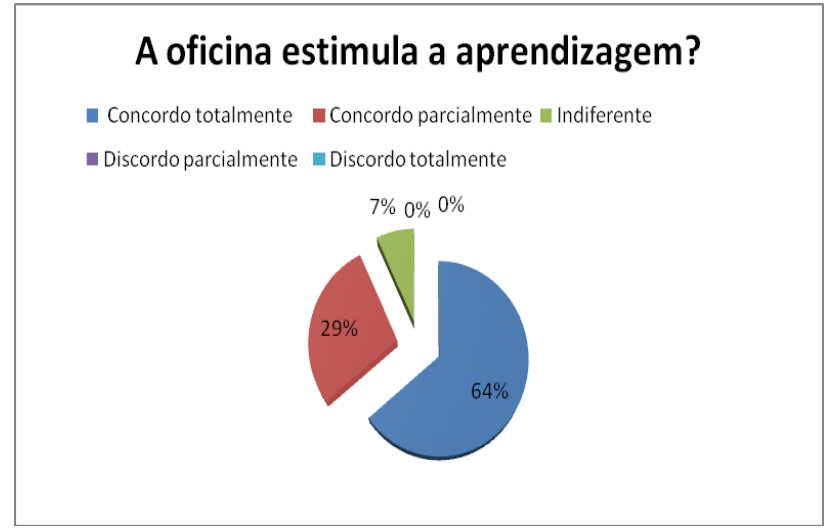

Gráfico 3 - Oficina e a aprendizagem 
Os resultados obtidos mostram que a oficina provocou conflitos cognitivos nos alunos, ao manusearem os espelhos, estimulando assim a curiosidade e proporcionando um caráter lúdico as aulas.

Quanto ao uso de TDIC, $86 \%$ da turma afirmou ser a primeira vez que usaram um objeto de aprendizagem virtual para simular o comportamento experimental de uma lente convergente. Nota-se que as respostas dos entrevistados confirmaram que não é costume dos professores fazerem uso dos TDIC, educando assim alunos do século XXI, que absorvem tudo muito facilmente e entendem o universo da informática quase que de modo natural (Gráfico 4).

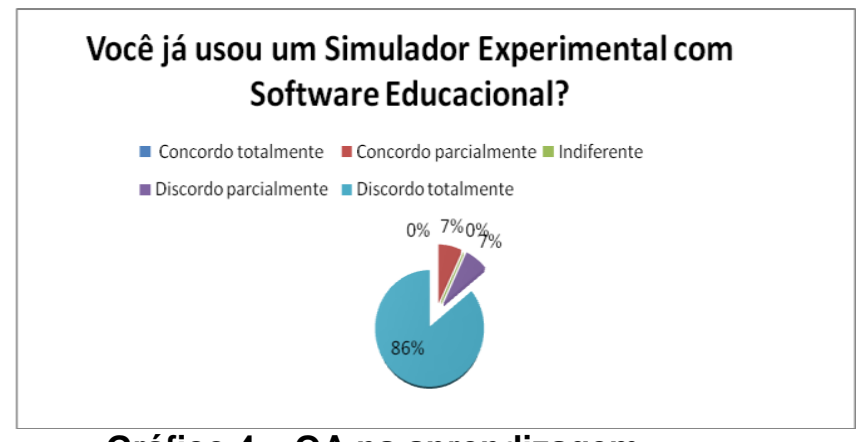

\section{Gráfico 4 - OA na aprendizagem}

Para analisar se realmente houve mudança de conceitos foi proposto e elaborado um Quiz que funcionou como ferramenta avaliativa, os alunos ainda não tinham sido avaliados por essa ferramenta. Pode-se verificar que 93\% da turma gostou da avaliação na forma de Quiz, ferramenta dinâmica que randomizava as questões e com o diferencial de retornos imediatos (feedback) às suas respostas.

Com relação à metodologia utilizada (Gráfico 5) todos responderam que as aulas de física se tornaram mais agradáveis: $50 \%$ da turma respondeu concordo totalmente, $50 \%$ concordo parcialmente, $0 \%$ foi indiferente, $0 \%$ discorda parcialmente e $0 \%$ discorda totalmente.

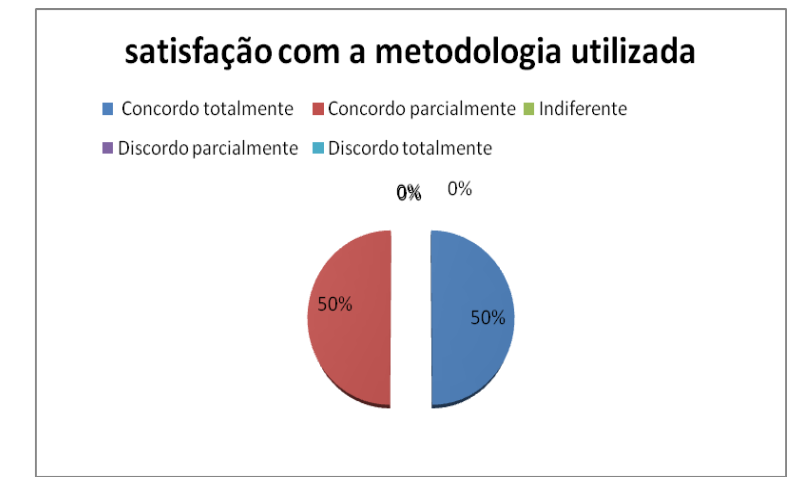

\section{Gráfico 5 - Satisfação com a metodologia}

É importante destacar que de acordo com a maioria dos alunos a metodologia ajudou bastante no aprendizado e que até o momento não foi utilizada por nenhum outro professor. Além disso, $79 \%$ da turma recomendaria essa metodologia a outros professores. 


\section{Considerações Finais}

Tendo em vista os objetivos propostos neste trabalho, percebe-se que o modelo de mudança conceitual proposto facilitou o processo de ensino e aprendizagem. Os resultados mostraram que as aulas de óptica geométrica baseada numa aprendizagem colaborativa apoiada por computador deram um caráter lúdico às aulas, o que facilitou a convergência dos conceitos prévios para conceitos científicos. Os resultados foram bastante animadores em termo de ocorrência de mudança conceitual, o que leva a acreditar no potencial das TDIC como ferramenta facilitadora no processo de mudança conceitual.

As TDIC não tiveram nesse trabalho a função de substituir o professor, mais de servir como mais uma ferramenta para auxiliar na atividade profissional. $O$ uso de tecnologias, já faz parte do cotidiano dos alunos, a escola tem que se aproximar desse cotidiano, para avança na sua missão. Utilizar as TDIC na sala de aula é uma forma de aproximar os alunos da escola.

Além disso, as TDIC são importantes para que os alunos se conectem com o mundo e aprendam fora da sala de aula, em qualquer tempo e em qualquer lugar. A escola precisa ser repensada, com o apoio das TDIC, como um conjunto de espaços e tempos significativos de aprendizagem que pode começar numa sala de aula, continuar numa biblioteca, em casa, ou em qualquer outro espaço.

Esta pesquisa teve suas limitações e dificuldades, afinal há muito de subjetividade quando se exploram mudanças conceituais, sugere-se que pesquisas posteriores possam envolver mais turmas de diferentes séries e conteúdos, para que se possam obter dados mais amplos, e assim, melhor validar o modelo dos 5 C's.

\section{Referências}

Alegro, Regina Célia. Conhecimento prévio e aprendizagem significativa de conceitos históricos no Ensino Médio. Marília: UNESP, 2008. Tese (Doutorado em Educação). Universidade Estadual Paulista "Julio de Mesquita Filho", Marília,2008.

Ausubel, D. P.; Novak, J. D., Hanesian, H. (1983). Psicología Educativa: un punto de vista cognoscitivo. México: Trillas.

Moreira, M. A. (2012). O Que é Afinal Aprendizagem Significativa. Revista Qurriculum, La Laguna. $\quad$ Disponível em< http://www.if.ufrgs.br/ moreira/ORGANIZADORESport.pdf $>$ Acesso em $12 / 02 / 2015$.

Posner, G.J.; Strike, K.A.; Hewson, P. W.; Gertzog, W.A (1982). Accommodation of a scientific conception: Toward a theory of conceptual change. Science Education, 66(2): 211-227.

Pozo, Juan Ignácio (1998). Teorias cognitivas da aprendizagem. Trad. Juan Acunã

Sales, G. L. (2005). QUANTUM: Um Software para Aprendizagem dos Conceitos da Física Moderna e Contemporânea. Dissertação de Mestrado. Fortaleza: UECE/CEFET-CE.

Sales, G. L. (2012). Uma Metodologia para desenvolver Objetos de Aprendizagem. Disponível: < http://professordenyssales.blogspot.com.br/2012_02_01_archive.html $>$. Acesso em 12/02/2015. 